\title{
LA TRIBUTACIÓN FAMILIAR
}

MARÍA TERESA SOLER ROCH

Universidad de Alicante

El deber de contribuir en nuestro ordenamiento jurídico tiene su fundamento en los principios proclamados en el artículo $31.1^{\circ}$ de la Constitución, según el cual: Todos contribuirán al sostenimiento de los gastos públicos:

- De acuerdo con su capacidad económica (principio de capacidad económica).

- Mediante un sistema tributario justo, inspirado en los principios de igualdad y progresividad que en ningún caso tendrá alcance confiscatorio (principios de justicia tributaria: igualdad y progresividad).

La aplicación de estos principios a la tributación familiar exige plantearse, previamente, dos cuestiones, a saber:

- ¿Es la familia una unidad económica? bros?

- ¿Incide la pertenencia a una familia en la posición económica de sus miem-

La respuesta a estas preguntas nos lleva a descubrir que, en el caso de la tributación familiar, la aplicación de aquellos principios se manifiesta a través de distintas paradojas que exponemos a continuación.

Primera, la paradoja de la capacidad económica ${ }^{1}$, en la medida en que la situación familiar, genera:

- Por un lado, una mayor capacidad económica, por el disfrute conjunto de rentas y patrimonios que genera economías de escala.

- Por otro lado, una menor capacidad económica. En general, por la existencia de cargas familiares; en particular, por los deberes económicos de la sociedad conyugal.

Segunda, la paradoja de la igualdad ${ }^{2}$, en la medida en que tener en cuenta la situación familiar, genera:

1. SOler Roch, María Teresa: «Subjetividad tributaria y capacidad económica de las personas integradas en unidades familiares», Civitas. Revista española de Derecho Financiero, 66 (1990), p. 203.

2. NúÑEZ GRAÑón, Mercedes: Las desigualdades tributarias por razones familiares y de residencia, Madrid, Instituto de Estudios Fiscales-Marcial Pons, 1998. 
- Por un lado, si la ley opta por una tributación exclusivamente individual, esta opción provoca una discriminación a favor / en contra de las unidades familiares.

- Por otro lado, si la ley opta por una tributación familiar (atendiendo sólo a familias legalmente constituidas), esta opción provoca una discriminación a favor / en contra de las uniones de hecho.

Tercera, la paradoja de la progresividad; en este caso, provocada por los efectos de la escala progresiva (aplicable en los impuestos directos que gravan la renta y el patrimonio de las personas físicas, así como en el impuesto sobre sucesiones y donaciones). Así:

- Por un lado, la aplicación de la escala a una base imponible conjunta implica una mayor cuota, mientras que su aplicación a bases imponibles separadas determina una cantidad menor resultante de la suma de las cuotas individuales.

- Por otro lado, en cuanto a las reducciones por cargas familiares: su aplicación sobre la base reduce la progresividad, mientras que su aplicación sobre la cuota mantiene la progresividad del gravamen.

Como no podía ser de otro modo, tratándose de la aplicación de principios constitucionales, la jurisprudencia constitucional, española y comparada, ha tenido ocasión de pronunciarse sobre estas cuestiones ${ }^{3}$; en concreto, en relación con la imposición sobre la renta de las personas físicas.

Dicha jurisprudencia se manifestó contraria a la tributación conjunta obligatoria en: Alemania (1957), Italia (1976), España (1989), siendo en todos los casos utilizados como principales argumentos:

- Los principios de igualdad y protección a la familia.

- La valoración de la capacidad económica individual.

- El perjuicio para el trabajo de la mujer casada.

Como consecuencia de esta doctrina jurisprudencial, la legislación comparada optó por diversas soluciones, así:

- Por un lado, distintas opciones de modelo único obligatorio, tales como: la tributación separada (total o parcial, sólo para determinadas rentas), el splitting (división de la renta entre ambos cónyuges) o el cociente familiar.

- Por otro lado, se produciría una eliminación del problema sustituyendo la tarifa progresiva por tipos proporcionales; pero ésta es una opción no elegida, por ahora, en ninguna jurisdicción fiscal (al menos por razones de tributación familiar $\left.{ }^{4}\right)$.

Los principales argumentos utilizados en su día por la jurisprudencia constitucional española se manifestaron en la sentencia 20/1989 del Tribunal Constitucional y fueron los siguientes:

3. Soler, María Teresa: Op. cit., p. 204.

4. La introducción del gravamen dual en el IRPF (2007) responde a la opción por una tributación más favorable del ahorro. 
- En relación con el principio de capacidad económica: la consideración de la individualidad del gravamen como un derecho fundamental.

- En relación con el principio de igualdad: los argumentos a favor de la tributación conjunta se dan en todo tipo de familia (legalmente constituida o de hecho).

- En relación con la protección a la familia: la aplicación de la tributación conjunta obligatoria sólo a las familias legales las discrimina frente a las uniones de hecho.

Las soluciones en Derecho español no se hicieron esperar; hubo una primera reforma de urgencia (1989) y un nuevo marco legal a partir de 1991, estableciendo un sistema de tributación familiar que se ha consolidado en reformas posteriores, incluyendo la proyectada reforma que entrará en vigor en 2007.

En relación con el IRPF, se regula un sistema dual consistente en:

- La tributación individual como regla general y,

- Una opción a la tributación conjunta para las unidades familiares conyugales y las unidades familiares monoparentales (con exclusión de las uniones de hecho).

En relación con la tributación individual, se establece la tributación individual obligatoria en cualquier caso (con independencia del hecho del matrimonio).

La exclusión de las meras uniones de hecho que no constituyan familia monoparental (parejas sin hijos) planteó, en un principio, nuevas dudas de constitucionalidad $^{5}$, que fueron solventadas a favor de la regulación legal, por el Tribunal Constitucional. En la sentencia 212/2001, argumentó el alto Tribunal que: «No basta con que, en situaciones puntuales, los sujetos puedan verse ocasionalmente beneficiados por no mantener una relación matrimonial».

En cuanto a la discriminación, entiende que se produce «sólo si la ley establece un régimen más gravoso en su conjunto para los sujetos casados que para quienes no lo están en atención, precisamente, a su situación patrimonial».

Mayores problemas se plantean en relación con el tratamiento de las uniones de hecho en el impuesto sucesorio. En este caso, se manifiesta, una vez más, la tensión dialéctica entre los principios de igualdad y seguridad jurídica ${ }^{6}$.

La legislación reguladora de este impuesto utiliza las expresiones "cónyuge» $\mathrm{y}$ «extraño» (esta última expresión en ausencia de parentesco), lo cual supone:

- Por un lado, que los beneficios fiscales (reducciones de la base imponible) se aplican sólo a los cónyuges.

- Por otro lado, que el incremento de la cuota en proporción al patrimonio preexistente del heredero, es menor en el caso de los cónyuges.

5. NúÑEz GraÑón, Mercedes: «Régimen tributario de las uniones de hecho», Revista Derecho privado y Constitución, Centro de Estudios Políticos y Constitucionales, 12 (1998), p. 197.

6. NúÑ̃E, Mercedes: Régimen tributario de las uniones..., op. cit., p. 209 y BAYONA JIMÉNEZ, J.J.: «Las uniones de hecho en el Impuesto sobre Sucesiones y Donaciones», Civitas. Revista española de Derecho Financiero, 93 (1997), p. 136. 
La combinación de estas dos circunstancias determina que la deuda tributaria de la pareja de hecho pueda llegar a ser muy superior a la que resultaría si tuviese la condición de cónyuge.

Aunque algunas Comunidades Autónomas han consagrado la equiparación de matrimonios y uniones de hecho, haciendo extensiva esta equiparación a la aplicación de las reducciones en el Impuesto de Sucesiones, no es ésta una solución generalizada que sólo podría venir a través de una modificación de la ley estatal reguladora del Impuesto sobre Sucesiones y Donaciones.

Mientras no se produzca esta reforma de la legislación estatal, habrá que tener en cuenta la doctrina jurisprudencial sobre la interpretación de la ley vigente, que ha rechazado la posibilidad de equiparar la pareja de hecho al cónyuge invocando la Ley General Tributaria que prohíbe la aplicación analógica de las normas sobre beneficios fiscales.

Volviendo a la tributación individual de los cónyuges en el impuesto sobre la renta, debe tenerse en cuenta la relación de las reglas de atribución de las distintas rentas en función de su origen con el régimen económico matrimonial, ya que las normas de titularidad civil van a afectar de forma distinta, de modo que:

- Las rentas del capital (mobiliario/inmobiliario), se atribuyen en función de la titularidad civil de los elementos patrimoniales que las producen.

- Las de trabajo y actividades económicas corresponden al cónyuge que realiza la actividad.

Esta diferencia de tratamiento ha sido objeto de consideraciones críticas desde la perspectiva del principio de igualdad, por considerar que favorece las rentas de capital y el régimen de gananciales.

También en este punto el Tribunal Constitucional ha considerado las citadas normas de atribución conformes con la Constitución. Así en relación con las rentas de trabajo en el régimen de gananciales, la sentencia 146/1994 estableció la siguiente doctrina:

«El problema constitucional de la imputación de rentas no reside en comprobar si las normas tributarias concuerdan con las civiles, sino en su conformidad con los principios constitucionales aplicables en la materia».

"Las rentas del capital compartido pueden imputarse por mitad, pero el hecho de que esta posibilidad no pueda hacerse con las rentas de trabajo, de condición estrictamente personal, no vulnera el principio de igualdad, pues ese diferente trato deriva de la distinta naturaleza de las fuentes productoras de ambas rentas».

La relación entre familia y capacidad económica en el IRPF es intrínseca a la propia naturaleza de este impuesto, como expresamente reconoce su Ley reguladora, cuando describe:

- Por un lado, su naturaleza: «impuesto personal que grava la renta de las personas físicas de acuerdo con sus circunstancias personales y familiares».

- Por otro lado, su objeto: «la capacidad económica del contribuyente, entendida ésta como su renta disponible, que será el resultado de disminuir la renta en la cuantía del mínimo personal y familiar». 
Esta relación se manifiesta, de modo más concreto, en el tratamiento legal de las cargas familiares, estableciendo al respecto una serie de medidas, tales como:

- El mínimo personal y por descendientes.

- Las reducciones en la base imponible por: edad, cuidado de hijos, asistencia y discapacitados.

- Un tratamiento específico para las madres trabajadoras, estableciendo una deducción específica por maternidad (hijos menores de tres años y alta en la Seguridad Social); deducción aplicable al padre en caso de fallecimiento de la madre o custodia exclusiva.

Por la misma razón, prevé la ley una serie de prestaciones familiares exentas del IRPF, tales como:

- Las prestaciones públicas por hijos (+ nacimiento, parto múltiple, adopción e hijos a cargo y orfandad) y por acogimiento (menores, minusválidos, mayores de 65 años).

- Las anualidades por alimentos y las percibidas de los padres en virtud de decisión judicial.

Una mención especial merece el tratamiento de las pensiones en el IRPF, debiendo distinguirse a este respecto entre:

- La pensión compensatoria al cónyuge, que se considera deducible para el cónyuge que la paga y renta de trabajo para el cónyuge que la recibe.

- La pensión a los hijos, que se considera no deducible para el padre o madre que la paga (aunque atenuando, en este caso, los efectos de la progresividad) y renta exenta para los hijos que la reciben.

En relación con este tratamiento de las pensiones, el Tribunal Constitucional, en sentencia de 15 enero 2001, estableció la siguiente doctrina:

"Aunque, desde luego, no existiría inconveniente constitucional alguno, el legislador tributario no ha previsto deducción alguna por la renta consumida en el deber de alimentos a los hijos».

"Con ello equipara la situación de estos padres a la de todos los que sufragan la manutención y educación de sus hijos sin que una decisión judicial lo imponga».

El tratamiento del patrimonio familiar en el Impuesto sobre el Patrimonio, se caracteriza, fundamentalmente por:

- El gravamen exclusivamente individual de todos y cada uno de los miembros de la familia.

- La atribución de los elementos patrimoniales según las reglas de titularidad civil (en el caso de los bienes comunes de los cónyuges, las que resulten aplicables en función del régimen económico o las capitulaciones matrimoniales).

- La exención de la vivienda habitual.

- Los beneficios fiscales aplicables a la empresa familiar (exención de los bienes y derechos afectos a la actividad o de las acciones y participaciones sociales correspondientes).

- Beneficios fiscales específicos para el patrimonio de los discapacitados. 
En cuanto a la responsabilidad patrimonial, la legislación aplicable considera obligados al pago de la deuda tributaria:

- En la tributación individual (IRPF, IP), la regla general es la asunción individual de la deuda correspondiente a cada miembro de la familia. Como regla especial, se establece el carácter ganancial de la deuda tributaria individual de cada cónyuge.

- En la tributación conjunta (IRPF), la ley establece la solidaridad de la deuda conjunta, sin perjuicio del prorrateo entre los contribuyentes de la unidad familiar.

La tributación de la disolución matrimonial afecta a supuestos de: separación legal, nulidad, divorcio o fallecimiento. En cuanto a sus efectos sobre la unidad familiar destaca:

- Por un lado, la opción a la tributación conjunta en la unidad monoparental resultante.

- Por otro lado, el tratamiento de las alteraciones patrimoniales que se producen como consecuencia de la disolución de la sociedad legal de gananciales y de las adjudicaciones resultantes en otros regímenes y cuya consecuencia más relevante, a efectos del IRPF es la no sujeción y el consiguiente diferimiento del gravamen.

Finalmente, en cuanto a la tributación de los no residentes, debe tenerse en cuenta que los impuestos que gravan la renta obtenida o el patrimonio situado en España por estos contribuyentes, al no imponer un gravamen sobre la renta o patrimonio mundial, se basan en el principio de tributación individual, siendo en principio, irrelevante, la situación familiar de estos contribuyentes.

Ello no obstante y teniendo en cuenta la doctrina establecida por el Tribunal de Justicia de la CE en punto al principio de no discriminación por razón de la residencia, la Ley española reguladora del Impuesto sobre la Renta de no Residentes prevé para los contribuyentes residentes en otro Estado miembro de la Unión Europea que obtenga en territorio español más del 75 de su renta procedente del trabajo o de actividades económicas, la opción a tributar por el IRPF pudiendo, además, en este caso, elegir entre las modalidades de tributación familiar (individual o conjunta) previstas en este impuesto7.

7. NÚÑEZ GRAÑóN, Mercedes: «Spanish Income Tax: option for residents of EU countries», EC Tax Review, 3 (1999). 